\title{
GNG7 silencing promotes the proliferation and differentiation of placental cytotrophoblasts in preeclampsia rats through activation of the mTOR signaling pathway
}

\author{
WEI-SI LAI and YI-LING DING \\ Department of Obstetrics and Gynecology, Second Xiangya Hospital, \\ Central South University, Changsha, Hunan 410011, P.R. China
}

Received August 3, 2018; Accepted February 8, 2019

DOI: $10.3892 /$ ijmm.2019.4129

\begin{abstract}
Preeclampsia (PE) is a pathological condition that manifests during pregnancy as the occurrence of an abnormal urine protein level and increased blood pressure due to inadequate cytotrophoblast invasion. To elucidate the mechanism underlying $\mathrm{PE}$, the present study primarily focused on the regulatory effects and mechanism of the G protein $\gamma 7$ (GNG7) on placental cytotrophoblasts in a rat PE model. Initially, the PE model was established with 45 specific pathogen-free Sprague-Dawley rats (30 females and 15 males). The expression patterns of GNG7, 4E-binding protein 1 (4E-BP1), phosphoprotein 70 ribosomal protein S6 kinase (p70S6K) and mammalian target of rapamycin (mTOR) were examined in the PE rats. Placental cytotrophoblasts isolated from normal and PE rats were treated with a small interfering RNA against GNG7, mTOR signaling pathway activator (HIV-1 Tat) or inhibitor (rapamycin). Following treatment, cell proliferation, differentiation and apoptosis were evaluated, and mTOR signaling pathway-related factors (4E-BP1, p70S6K and mTOR), cell proliferation-related factors (vascular endothelial growth factor and transforming growth factor- $\beta 1)$, differentiation-related factors [activator protein-2 (AP-2) $\alpha$ and AP-2 $\gamma$ ], and apoptosis-related factors [B-cell lymphoma 2 (Bcl-2) and Bcl-2-associated X protein] were determined. Finally, soluble fms-like tyrosine kinase 1 (sFlt-1) and soluble endoglin (sEng) levels were measured via enzyme-linked immunosorbent assay. Initially, the mTOR signaling pathway was inactivated in the placental tissues and cytotrophoblasts in the PE rats. Silencing GNG7 reduced the levels of sFlt-1 and sEng and activated the mTOR signaling pathway. Silencing of GNG7
\end{abstract}

Correspondence to: Dr Yi-Ling Ding, Department of Obstetrics and Gynecology, Second Xiangya Hospital, Central South University, 139 Renmin Middle Road, Changsha, Hunan 410011, P.R. China

E-mail: drdingyiling@163.com

Key words: G protein $\gamma 7$, mammalian target of rapamycin, preeclampsia, placental trophoblast, proliferation, differentiation or activation of the mTOR signaling pathway enhanced cell proliferation and differentiation, but inhibited the apoptosis of placental cytotrophoblasts in the PE rats. Taken together, the results showed that GNG7 silencing repressed apoptosis and enhanced the proliferation and differentiation of placental cytotrophoblasts in PE rats through activation of the mTOR signaling pathway.

\section{Introduction}

Preeclampsia (PE) is the main cause of maternal mortality and morbidity worldwide. Marked decreases in eclampsia rates and maternal mortality and morbidity rates have been recorded in developed countries over the past five decades (1). The persistent high occurrence in developing countries has been reported to be mainly due to inadequate prenatal care (2). PE complications lead to an annual maternal mortality rate of $>5,000$. The maternal mortality rates in developing countries are $>15 \%$, compared with rates of $0-1.8 \%$ in developed countries due to lack of access to appropriate maternal care (3). However, studies have suggested that eculizumab, a targeted inhibitor of complement protein $\mathrm{C} 5$, may result in significant clinical improvement for patients with severe PE/HELLP syndrome at the 26th week of pregnancy, resulting in complete normalization of laboratory parameters (4). Additionally, the human protein $\alpha 1$-microglobulin (A1M), an endogenous antioxidation protection protein, has been shown to protect the placenta from hemoglobin-induced damage and restore the blood-placental barrier, suggesting that A1M may contribute to future pharmacological treatment for PE (5). Genetic mutations and regulatory mechanisms in PE require clarification to identify an effective and safe strategy for its treatment.

G protein $\gamma 7$ (GNG7) is a subunit of a heterotrimeric $\mathrm{G}$ protein with ubiquitous expression in various tissues but low expression in cancer (6). This protein may be associated with transmembrane signaling pathways and involved in cell contact-induced growth arrest, thus repressing uncontrolled cell proliferation in multicellular organisms (7). Data from previous studies suggest that the components of $\mathrm{G}$ protein signaling pathways, including regulator of $\mathrm{G}$-protein signaling 2 and rs4606, may have effects on the progression and risk of PE (8). In addition, the mammalian target 
of rapamycin (mTOR) signaling pathway can be inhibited by GNG7 which is involved in autophagy and cell death (6). mTOR, which is a serine/threonine protein kinase that encompasses two multiprotein complexes (mTORC1 and mTORC2), has been demonstrated to be a downstream marker of the phosphoinositide 3-kinase/AKT signaling pathway (9). Of critical importance, mTOR, which is ubiquitously expressed in cells, can be regarded as a therapeutic target for cancer in humans (10). In addition, activation of the mTOR signaling pathway has been demonstrated to improve the pregnancy outcomes of rats induced by $\mathrm{N}$-carbamylglutamate (11). A previous study confirmed that suppression of the mTOR signaling pathway induces the occurrence of PE through decreasing the invasion ability of trophoblast cells (12). Consequently, GNG7 and the mTOR signaling pathway may be involved in the proliferation and apoptosis of placental cytotrophoblasts in PE. Therefore, the present study examined the effects of GNG7 on PE through the mTOR signaling pathway to provide a theoretical basis for $\mathrm{PE}$ treatment in the near future.

\section{Materials and methods}

Ethics statement. The present study was conducted in strict accordance with the recommendations in the Guide for the Care and Use of Laboratory Animals of the National Institutes of Health. The protocol was approved by the Institutional Animal Care and Use Committee of Second Xiangya Hospital, Central South University (Changsha, China).

Model establishment. A total of 45 specific pathogen-free Sprague-Dawley rats (30 females and 15 males) aged 2-3 months and weighing 200-220 g were purchased from the Medical Experimental Animal Center of Guangdong Province (Guangdong, China). The mice were acclimatized for 1 week and housed in well-ventilated cages at $25-26^{\circ} \mathrm{C}$ with a relative humidity of $\sim 70 \%$, regular ultraviolet disinfection, light exposure between 6:00 a.m. and 6:00 p.m., and free intake of food and water. The rats were then mated (2:1 female:male), and vaginal smears were collected the following morning and observed under a microscope. The day on which the presence of sperm was observed on the smears was defined as pregnancy day 0 . A total of 25 pregnant rats were randomly classified into the PE group (12 rats) and the normal group (10 rats) on the 5th to 10th days of pregnancy, and the remaining three rats were used for the follow-up experiments. From the 10th day of pregnancy, NG-nitro-L-arginine methyl ester at a dose of $100 \mathrm{mg} /(\mathrm{kg} \cdot \mathrm{day})$ was continuously and subcutaneously injected into the rats in the PE group, and the same volume of normal saline was injected into the rats in the normal group. PE manifestations in the rats a included higher systolic blood pressure (BP) of $110.12 \pm 5.73 \mathrm{mmHg}$ and urine protein $(6.33 \pm 0.42 \mathrm{mg} / 24 \mathrm{~h})$ on the 18th day of pregnancy compared with those in the normal group, indicating successful establishment of the PE model (13).

The mother rats were sacrificed following cesarean delivery to collect the uterine placenta. Part of the uterine placenta tissue was used for extraction and detection of total protein and RNA, and the isolation and culture of primary cytotrophoblasts; and the other part was preserved for the other follow-up experiments.
$B P$ measurement. The BP of the rats was measured with the tail-cuff method using a Coda noninvasive BP system (Kent Scientific Corporation, Torrington, CT, USA) on the 6th, 12th and 18th days of pregnancy. The BP measurement was performed at 8:00 a.m. with the following requirements: First, the rats were fasted for $2 \mathrm{~h}$ prior to measurement and then placed on a preheated thermostat $\left(37^{\circ} \mathrm{C}\right)$ for $10 \mathrm{~min}$ prior to measurement; subsequently, during measurement, the room temperature was set at $25^{\circ} \mathrm{C}$, and the $\mathrm{BP}$ of the rats was measured using the preadjusted tail-cuff device with the clamp placed at the root of the rat tails when their heart rates were stable. The BP of each rat was measured three times and then averaged.

Automatic biochemical analysis. Urine was collected from the rats in each group on the 6th, 12th and 18th days of pregnancy to detect the urine protein levels through full automatic biochemical analysis. Following $10 \mathrm{~min}$ of centrifugation of the urine at $717 \mathrm{xg}$ and $4^{\circ} \mathrm{C}$, the sediment was removed. Biuret reagent (HPBIO-R1253, Pengpai Biotech Company, Shanghai, China) was then added to the urine samples to detect urine proteins. On the 21st day of pregnancy, the rat placental tissues were obtained from the uterus following cesarean delivery; part of the tissue was used for the extraction and detection of total protein and RNA and for primary cytotrophoblast isolation, and the remainder was fixed for use in the other follow-up experiments.

Hematoxylin and eosin $(H \& E)$ staining. The placental tissues preserved in $4 \%$ formalin were obtained, dehydrated in gradient alcohol (75, 80, 90, 95 and 100\%) twice for $1.5 \mathrm{~h}$ each series, and cleared with xylene twice for 8 min each time. Subsequently, the tissues were embedded in paraffin and sliced into 5-7- $\mu \mathrm{m}$-thick slices using a microtome (RM2016; Leica, Shanghai, China). The slices were then incubated at $55^{\circ} \mathrm{C}$, deparaffinized in xylene and hydrated with gradient alcohol at concentrations of 100, 95, 85 and $75 \%$ (3 min each concentration). The tissues were then stained with hematoxylin for $8 \mathrm{~min}$, washed with water for $2 \mathrm{~min}$, differentiated with hydrochloric alcohol for $5 \mathrm{sec}$, and washed with water for $2 \mathrm{~min}$. The tissues were treated with $0.25 \%$ ammonia for $1 \mathrm{~min}$ and washed with water for $2 \mathrm{~min}$. Subsequently, the tissues were stained using eosin for $30 \mathrm{sec}$ and washed with water for 2 min prior to dehydration twice with a gradient alcohol series (85, 95 and $100 \%$; 2 min for each) and xylene clearing twice (5 min each). When the staining was completed, the sample slides were mounted using neutral balsam and sealed with clean cover slips. The histopathological changes in the placenta were observed under a microscope (XSP-2C; Bingyu Optical Instrument Co., Ltd., Shanghai, China).

Immunohistochemistry. The placental tissues immersed in $4 \%$ paraformaldehyde at $4^{\circ} \mathrm{C}$ were collected and dehydrated. The paraffin-embedded tissues were sectioned into 5- $\mu \mathrm{m}$-thick slices, dewaxed, and stained with H\&E. Following air-drying at room temperature for $24 \mathrm{~h}$, the slices were placed into a phosphate-buffered saline (PBS) container ( $\mathrm{pH}$ 7.4) and diluted with $0.05 \mathrm{~mol} / \mathrm{dm}^{3}$ tris(hydroxymethyl)aminomethane hydrochloride containing 1\% bovine serum albumin (BSA; Yancheng Saibao Biotechnology Co., Ltd., Yancheng, China) at $\mathrm{pH}$ 7.6. The slices were labeled with a modified 
biotinylated anti-rat immunoglobulin for $15 \mathrm{~min}$. The slices were then incubated with primary antibodies at $4^{\circ} \mathrm{C}$ overnight, including polyclonal rabbit anti-4E-BP1, 4E-binding protein 1 (4E-BP1; 1:100, cat. no. ab2606), phosphoprotein 70 ribosomal protein S6 kinase (p70S6K; 1:100, cat. no. ab59208) and mTOR (1:100, cat, no. ab2732), and then washed three times in PBS for 5 min per wash. The above antibodies were all procured from Abcam (Cambridge, MA, USA). Subsequently, the slices were incubated with the secondary antibody (goat anti-rabbit immunoglobulin G, IgG, 1:1,000, cat. no. ab6721; Abcam) at $37^{\circ} \mathrm{C}$ for $30 \mathrm{~min}$. The staining results were observed and images were captured under an optical microscope (14). Five high-magnification fields with 100 cells per field were randomly selected for each slice. The staining intensity was graded as follows: $<10 \%$ positive cells, negative; $\geq 10$ and $<50 \%$, positive; and $\geq 50 \%$ positive cells, strongly positive.

Reverse transcription-quantitative polymerase chain reaction $(R T-q P C R)$ analysis. Total RNA was extracted from the placental tissue samples or transfected cytotrophoblast cells using the TRIzol reagent one-step method according to the manufacturer's protocol (Invitrogen; Thermo Fisher Scientific, Inc., Waltham, MA, USA). The extracted RNA was then reverse transcribed into complementary DNA (cDNA) following the two-step instructions of the PrimeScript ${ }^{\mathrm{TM}}$ RT Reagent kit (RR037Q; Takara Biotechnology, Co., Ltd., Dalian, China) in a reaction system that contained $2 \mu 1$ of $5 \mathrm{X}$ PrimeScript buffer (for real time), $0.5 \mu 1$ of PrimeScript RT Enzyme mix I, $0.5 \mu \mathrm{l}$ of the Oligo dT primer $(50 \mu \mathrm{M}), 0.5 \mu \mathrm{l}$ of random 6-mers $(100 \mu \mathrm{M}), 2 \mu \mathrm{g}$ of total RNA and RNase-free $\mathrm{dH}_{2} \mathrm{O}$ to a total volume of $20 \mu \mathrm{l}$. The reaction was conducted under the following conditions: Reverse-transcribed at $37^{\circ} \mathrm{C}$ for $15 \mathrm{~min}$, inactivation of reverse transcriptase at $85^{\circ} \mathrm{C}$ for $5 \mathrm{sec}$. The cDNA was temporarily preserved at $-80^{\circ} \mathrm{C}$. Subsequent RT-qPCR analysis was conducted using the TaqMan probe method, and the reaction system was performed according to the instructions of the kit purchased from Marrone Bio Innovations, Inc. (MBI, Davis, CA, USA). The primer sequences are shown in Table I and the reaction conditions were as follows: Predenaturation at $95^{\circ} \mathrm{C}$ for $30 \mathrm{sec}$ and 40 cycles of denaturation at $95^{\circ} \mathrm{C}$ for $10 \mathrm{sec}$, annealing at $60^{\circ} \mathrm{C}$ for $20 \mathrm{sec}$ and extension at $72^{\circ} \mathrm{C}$ for $10 \mathrm{sec}$. The reaction system included $12.5 \mu 1$ of Premix Ex Taq or SYBR-Green Mix, $1 \mu \mathrm{l}$ of the forward primer, $1 \mu \mathrm{l}$ of the reverse primer, 1-4 $\mu \mathrm{l}$ of cDNA and $\mathrm{ddH}_{2} \mathrm{O}$ to a total volume of $25 \mu \mathrm{l}$. The relative expression levels were determined using a Real-Time PCR instrument (Bio-Rad iQ5; Bio-Rad Laboratories, Inc., Hercules, CA, USA) with glyceraldehyde-3-phosphate dehydrogenase (GAPDH) as an internal reference. The primer sequences shown in Table I were synthesized by Shanghai Generay Biotech Co., Ltd. (Shanghai, China), and the reliability of the PCR results was evaluated using melting curve analysis. The quantification cycle $(\mathrm{Cq})$ was obtained and used in the following formulas: $\Delta \mathrm{Cq}=\mathrm{Cq}_{\text {(target gene) }}-\mathrm{Cq}_{(\mathrm{GAPDH})}$, and $\Delta \Delta \mathrm{Cq}=\Delta \mathrm{Cq}_{\text {(experiment group) }}-\Delta \mathrm{Cq}_{\text {(control group) }}$ (15). The experiment was repeated three times, and the average values were obtained.

Western blot analysis. The total proteins were extracted from the placental tissues isolated from each group of rats and the protein concentration was measured using the bicinchoninic acid assay. The tissues were treated with $5 \mathrm{X}$ sodium dodecyl sulfate lysis buffer (P0013G; Beyotime Institute of Biotechnology, Beijing, China) and boiled at $100^{\circ} \mathrm{C}$ for $5 \mathrm{~min}$ to denature the proteins. The proteins $(20 \mu \mathrm{l})$ were loaded onto a polyacrylamide gel composed of a 5\% stacking gel and a $12 \%$ separating gel for electrophoresis. Following transfer, the membrane was blocked for $1 \mathrm{~h}$ on a shaker at room temperature using Tris-buffered saline + Tween (TBST) with 5\% BSA. The blocking solution was then discarded, and the membrane was placed into a plastic slot and oscillated overnight at $4^{\circ} \mathrm{C}$ with the following primary antibodies diluted with 5\% BSA: Polyclonal rabbit anti-rat GNG7 $(1 \mu \mathrm{g} / \mathrm{ml}$, cat. no. ab169493), polyclonal rabbit anti-rat 4E-BP1 (1:1,000, cat. no. ab2606), polyclonal rabbit anti-rat p70S6K (1:250, cat. no. ab9366), polyclonal rabbit anti-rat mTOR (1:2,000, cat. no. ab2732), polyclonal rabbit anti-rat phosphorylated (p-)4E-BP1 $(1: 1,000$, cat. no. ab47365), polyclonal rabbit anti-rat p-p70S6K $(2 \mu \mathrm{g} / \mathrm{ml}$, cat. no. ab2571), monoclonal rabbit anti-rat mTOR (1:2,000, cat. no. ab109268), polyclonal rabbit anti-rat vascular endothelial growth factor (VEGF; $3 \mu \mathrm{g} / \mathrm{ml}$, cat. no. ab11939), polyclonal rabbit anti-rat transforming growth factor- $\beta 1$ (TGF- $\beta 1 ; 3 \mu \mathrm{g} / \mathrm{ml}$, cat. no. ab92486), polyclonal rabbit anti-rat activator protein- $2 \gamma$ (AP-2 $\gamma ; 1: 1,000$, ab203691), polyclonal rabbit anti-rat AP-2 $\alpha$ (1:1,000, cat. no. ab108311), monoclonal rabbit anti-rat B-cell lymphoma 2 (Bcl-2)-associated X protein (Bax; 1:1,000, cat. no. ab53154), and monoclonal rabbit anti-rat Bcl-2; 1:500, cat. no. ab59348) (all purchased from Abcam). GAPDH (1:1,000, cat. no. ab8245, Abcam) was used as an internal reference. The following day, the membrane was rinsed three times with TBST (10 min each), incubated with a diluted secondary antibody (goat anti-rabbit IgG, 1:2,000, cat. no. ab6721; Abcam) at $4^{\circ} \mathrm{C}$ for $4-6 \mathrm{~h}$ and then washed three times with TBST (15 min each). Chemiluminescence reagents A and B (Yanhui Biological Co., Ltd., Shanghai, China) were mixed at a 1:1 ratio and evenly dropped onto the nitrocellulose membrane for image development. Using the gray value ratio of the target band to the GAPDH band to represent relative protein expression, the relative optical density (OD) value was analyzed for all bands. The experiment was repeated three times, and the average values were calculated.

Cell isolation, culture and transfection. The placental tissues were cut into slices with a thickness of $\sim 3 \mathrm{~mm}$ and detached with $2.5 \mathrm{~g} / \mathrm{l}$ of trypsin in a $37^{\circ} \mathrm{C}$ water bath three times for 10 min each time. The obtained cell suspension was then centrifuged at $225 \mathrm{x} \mathrm{g}$ for $5 \mathrm{~min}$ at $37^{\circ} \mathrm{C}$, washed twice with PBS and resuspended in Dulbecco's modified Eagle's medium/F12 (HyClone; GE Healthcare Life Sciences, Logan, UT, USA) containing $100 \mathrm{ml} / 1$ of fetal bovine serum (TBD Sciences, Tianjin, China). The cells were then inoculated into the culture plate and incubated in a $37^{\circ} \mathrm{C}$ and $5 \% \mathrm{CO}_{2}$ incubator. Epithelioid cells growing in a lamellar shape were observed under an inverted microscope. The cells identified as cytotrophoblasts without parenchymal cells were further cultured in a $37^{\circ} \mathrm{C}$ and $5 \% \mathrm{CO}_{2}$ incubator. Following cell passage, the third generation cytotrophoblasts were used for transfection.

Placental cytotrophoblasts isolated from the normal and $\mathrm{PE}$ rats were assigned into the normal group (cytotrophoblasts 
Table I. Primer sequences for reverse transcription-quantitative polymerase chain reaction analysis.

\begin{tabular}{|c|c|}
\hline Gene & Primer sequence $\left(5^{\prime}-3^{\prime}\right)$ \\
\hline \multirow[t]{2}{*}{ GNG7 } & F: TTAGGTGTGCCAGTGTGGTC \\
\hline & R: CCATGGGCAGTTTGAGCAAC \\
\hline \multirow[t]{2}{*}{ 4E-BP1 } & F: AAAGGATCCGGGGGCAGCAGGTGCAGCCAGACCC \\
\hline & R: AAACTCGAGTTACTGTGACTCTTCACCGACCCGCC \\
\hline \multirow[t]{2}{*}{ p70S6K } & F: CTACAGAGACCTGAAGCCGGAGA \\
\hline & R: AATGTGTGCGTGACTGTTCCATC \\
\hline \multirow[t]{2}{*}{ mTOR } & F: ATGACGAGACCCAGGCTAA \\
\hline & R: GCCAGTCCTCTACAATACGC \\
\hline \multirow[t]{2}{*}{ VEGF } & F: TGCTCCATTCTGTAGGCTCTG \\
\hline & R: CTGGCCCATAAATCATCCC \\
\hline \multirow[t]{2}{*}{ TGF- $\beta 1$} & F: CGAGGTGACCTGGGCACCATCCATGAC \\
\hline & R: CTGCTCCACCTTCTTGGGCTTGCGACCCAC \\
\hline \multirow[t]{2}{*}{$\mathrm{AP}-2 \gamma$} & F: CGCATCCCTCACCTCTCATC \\
\hline & R: TAATGATCGGCGGATTGCGA \\
\hline \multirow[t]{2}{*}{ AP- $-2 \alpha$} & F: CGCGGATCCACCACCATGGGCATGCTTTGGAAACTGACGGATAAT \\
\hline & R: CCCAAGCTTTCACTTTCTGTGTTTCTCTTCTTTG \\
\hline \multirow[t]{2}{*}{ Bax } & F: AGACACCTGAGCTGACCTTGGAG \\
\hline & R: GTTGAAGTTGCCATCAGCAAAC \\
\hline \multirow[t]{2}{*}{ Bcl-2 } & F: TGAACCGGCATCTGCACAC \\
\hline & R: CGTCTTCAGAGACAGCCAGGAG \\
\hline \multirow[t]{2}{*}{ GAPDH } & F: GGCACAGTCAAGGCTGAGAATG \\
\hline & R: ATGGTGGTGAAGACGCCAGTA \\
\hline
\end{tabular}

F, forward; R, reverse; GNG7, G protein $\gamma$ 7; 4E-BP1, 4E-binding protein 1; p70S6K, phosphoprotein 70 ribosomal protein S6 kinase; mTOR, mammalian target of rapamycin; VEGF, vascular endothelial growth factor; TGF- $\beta 1$, transforming growth factor- $\beta 1$; AP- $2 \gamma$, activator protein-2 $\gamma$; AP-2 $\alpha$, activator protein-2 $\alpha$; Bcl-2, B-cell lymphoma 2; Bax, Bcl-2-associated X protein; GAPDH, glyceraldehyde-3-phosphate dehydrogenase.

isolated from normal rats), blank group (cytotrophoblasts isolated from PE rats without any treatment), negative control (NC) group (cytotrophoblasts isolated from PE rats transfected with the empty plasmid), GNG7-siRNA group [cytotrophoblasts isolated from PE rats transfected with the GNG7-small interfering (si)RNA plasmid], HIV-1 Tat group (cytotrophoblasts isolated from PE rats treated with the mTOR activator HIV-1 Tat, 48-60; Seebio Biotech, Inc., Shanghai, China), GNG7-siRNA + HIV-1 Tat group (cytotrophoblasts isolated from PE rats transfected with the GNG7-siRNA plasmid and treated with the mTOR activator HIV-1 Tat), GNG7-siRNA + dimethylsulfoxide (DMSO) group (cytotrophoblasts isolated from PE rats treated with GNG7-siRNA and DMSO) and GNG7-siRNA + rapamycin group (cytotrophoblasts isolated from PE rats treated with GNG7-siRNA and the mTOR inhibitor rapamycin). Placental cytotrophoblasts at the logarithmic growth phase were inoculated into a 6-well plate and transfected with Lipofectamine 2000 reagent in accordance with the manufacturer's protocol (Invitrogen; Thermo Fisher Scientific, Inc.) when cell confluence reached 30-50\%. Subsequently, 100 pmol of GNG7-siRNA and the empty plasmid were separately diluted using $250 \mu \mathrm{l}$ of Opti-MEM serum-free medium (Gibco; Thermo Fisher Scientific, Inc.) to a final concentration of $50 \mathrm{nM}$ and incubated at room temperature for $5 \mathrm{~min}$. Subsequently, $5 \mu \mathrm{l}$ of Lipofectamine 2000 was diluted with $250 \mu \mathrm{l}$ of serum-free Opti-MEM and incubated at room temperature for $5 \mathrm{~min}$. The above two dilutions were mixed together and incubated at room temperature for $20 \mathrm{~min}$ prior to inoculation into the cell culture plates. Following 6-8 h of incubation at $5 \% \mathrm{CO}_{2}$ and $37^{\circ} \mathrm{C}$, the cells were cultured in complete medium for another 1 or 2 days and then used for the follow-up experiments.

3-(4,5-Dimethyl-2-thiazolyl)-2,5-diphenyl-2-H-tetrazolium bromide (MTT) assay. Cells in the logarithmic growth phase were inoculated into a 96 -well plate $\left(1 \times 10^{5}\right.$ cells $\left./ \mathrm{ml}\right)$ and assigned to six groups (8 wells per group; $100 \mu 1$ per well) and cultured in an incubator with $5 \% \mathrm{CO}_{2}$ at $37^{\circ} \mathrm{C}$. After 24, 48 and $72 \mathrm{~h}$ of culture, each well was supplemented with $10 \mu \mathrm{l}$ of MTT solution ( $5 \mathrm{mg} / \mathrm{ml}$, SBJ-0190; Nanjing SenBeiJia Biological Technology Co., Ltd., Nanjing, China) and incubated for an additional $4 \mathrm{~h}$. The OD values of each well were measured at $570 \mathrm{~nm}$ using a microplate reader.

Flow cytometry. Following $48 \mathrm{~h}$ of transfection, the cell culture medium was discarded, and the cells were washed with PBS once, treated with $0.25 \%$ trypsin and then collected. Annexin V and propidium iodide (PI) staining (R\&D Systems, Inc., Minneapolis, MN, USA) was conducted using an in situ apoptosis detection kit. The cells were suspended in $80 \mu \mathrm{l}$ of 
Table II. BP and urinary protein levels prior to modeling and on days 12 and 18 after modeling.

PE group $(n=12)$

\begin{tabular}{lcccc}
\cline { 3 - 5 } Indicator & Normal group $(\mathrm{n}=10)$ & Pre-modeling & Day 12 after modeling & Day 18 after modeling \\
\hline Systolic BP $(\mathrm{mmHg})$ & $108.74 \pm 9.03$ & $114.90 \pm 11.06$ & $132.78 \pm 12.35^{\mathrm{a}}$ & $148.23 \pm 13.64^{\mathrm{a}}$ \\
Diastolic BP (mmHg) & $81.29 \pm 8.12$ & $79.81 \pm 6.42$ & $95.45 \pm 7.67^{\mathrm{a}}$ & $104.95 \pm 9.43^{\mathrm{a}}$ \\
24-h urine protein $(\mathrm{mg})$ & $6.51 \pm 0.84$ & $6.68 \pm 0.71$ & $8.56 \pm 0.52^{\mathrm{a}}$ & $11.37 \pm 1.14^{\mathrm{a}}$ \\
\hline
\end{tabular}

${ }^{a} \mathrm{P}<0.05$ compared with the normal group. The results of tail BP and automatic biochemical analysis of urine protein levels in rats pre- and post-modeling were measured. Data ere expressed as mean \pm standard deviation and were analyzed using an unpaired t-test. The experiment was repeated three times. PE, preeclampsia; BP, blood pressure.

balanced salt solution that included $10 \mathrm{mmol} / \mathrm{l}$ of HEPES, $140 \mathrm{mmol} / \mathrm{l}$ of sodium chloride and $2.5 \mathrm{mmol} / 1$ of calcium chloride (pH 7.4). To each cell suspension, $10 \mu \mathrm{l}$ of Annexin V $(10 \mu \mathrm{g} / \mathrm{ml})$ and $10 \mu \mathrm{l}$ of PI reagent $(50 \mu \mathrm{g} / \mathrm{ml})$ were added. The cells were mixed and incubated at room temperature for $15 \mathrm{~min}$, and then $400 \mu \mathrm{l}$ of buffer salt solution was added. Apoptosis and the cell cycle distribution were immediately analyzed by flow cytometry. Control tubes of unstained cells, PI single-stained cells and Annexin V-stained cells were included to set the flow cytometric compensation. Subsequently, the cells were analyzed using a flow cytometer (FACSCalibur; BD Biosciences, Franklin Lakes, NJ, USA), and the cell cycle distribution and induction of apoptosis were evaluated when red fluorescence was detected at an excitation wavelength of $488 \mathrm{~nm}$. The experiment was repeated three times.

Enzyme-linked immunosorbent assay (ELISA). The supernatants were collected from cell cultures in each group. The soluble fms-like tyrosine kinase 1 (sFlt-1) and soluble endoglin (sEng) levels were determined according to the instructions of the ELISA kits (Abcam). The absorbance value $\mathrm{A}_{450}$ was measured at the $450 \mathrm{~nm}$ wavelength. Three parallel wells were set for each sample, and the mean value was obtained.

Statistical analysis. All data were processed with SPSS 21.0 statistical software (IBM Corp., Armonk, NY, USA). Measurement data are expressed as the mean \pm standard deviation, and differences in normally distributed and homogeneous data between two groups were examined with an unpaired t-test. One-way analysis of variance (ANOVA) was performed for comparison among multiple groups. Comparisons of normally distributed data among multiple groups were performed using Tukey's post hoc test. A repeated measures ANOVA was conducted to assess cell viability at different time points. $\mathrm{P}<0.05$ was considered to indicate a statistically significant difference.

\section{Results}

PE model establishment with higher systolic/diastolic BP and urine protein levels. To verify successful establishment of the PE model, tail-cuff BP measurement and automatic biochemical analysis were performed. Prior to pregnancy, no significant differences in systolic/diastolic BP or urine protein were
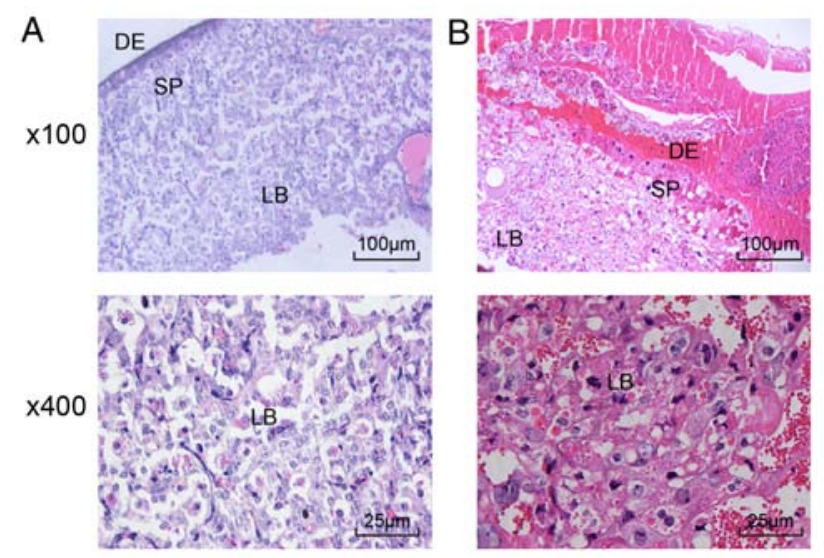

Figure 1. Proliferation and differentiation of placental trophoblasts are suppressed in PE rats (magnification, x100). (A) H\&E staining of placental tissues of normal rats. In normal rats, the placental villi were dominated by syncytiotrophoblasts. (B) H\&E staining of placental tissues of PE rats. In the PE rats, the placental villi were characterized by cytotrophoblast cell proliferation, immature villi, nonuniform placental decidua mesenchymal cells, decidual vascular endothelial cell fibrosis and notably increased decidual fibrous necrosis. H\&E, hematoxylin and eosin; PE, preeclampsia; LB, labyrinth; DE, decidua; SP, spongiotrophoblast.

observed between the normal and $\mathrm{PE}$ rats $(\mathrm{P}<0.05)$. On the 12 th and 18th days of pregnancy, the systolic/diastolic BP and urine protein were increased in the PE rats compared with those in the normal rats. As shown in Table II, the systolic/diastolic $\mathrm{BP}$ and urine protein values were all increased in the PE rats, suggesting that the PE model was successfully established.

Proliferation and differentiation of placental cytotrophoblasts are suppressed in PE rats. H\&E staining was performed to observe histopathological changes of the placenta in the normal and PE rats. The results (Fig. 1A and B) demonstrated that the cytotrophoblasts in the placental villi invaded into the mesometrium in the normal rats, whereas the placental villi in the $\mathrm{PE}$ rats showed limited cytotrophoblast invasion, narrow spiral arterioles, hyperplastic endothelial cells, capillary occlusion, placental tissue apoptosis, detachment of endothelial cells from the basilar membrane, presence of macrophages in the thrombus area and transformation of cytotrophoblasts into syncytiotrophoblasts (16). Additionally, the placental villi in the PE rats were characterized by nonuniform placental decidual mesenchymal cells, decidual vascular endothelial cell 

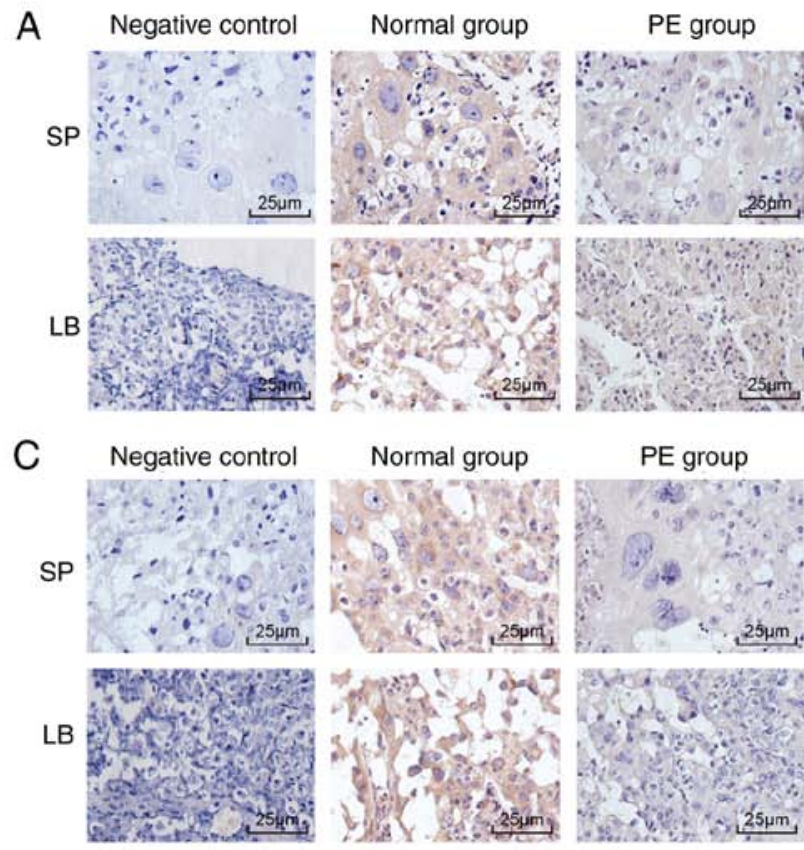
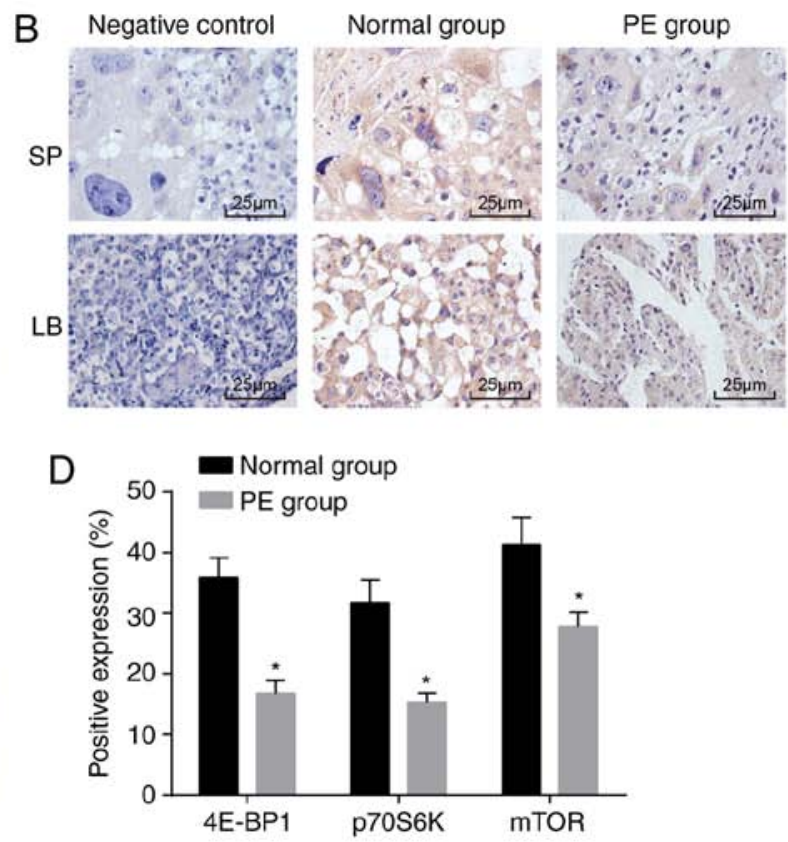

Figure 2. 4E-BP1, p70S6K and mTOR are reduced in placental tissues from PE rats. (A) Immunohistochemical staining showing positive expression of mTOR (magnification, x400); (B) positive expression of 4E-BP1 in placental tissues of PE rats detected by immunohistochemical staining (magnification, x400); (C) positive expression of p70S6K in the PE placenta detected by immunohistochemical staining (magnification, $\mathrm{x} 400$ ); (D) protein expression of 4E-BP1, p70S6K and mTOR in placental tissues from PE rats; ${ }^{*} \mathrm{P}<0.05$ compared with the normal rats. The measurement data are expressed as the mean \pm standard deviation and were analyzed with an unpaired t-test. The sample size of the normal group was $n=10$ and of the PE group was $n=12$; mTOR, mammalian target of rapamycin; 4E-BP1, 4E-binding protein 1; p70S6K, phosphoprotein 70 ribosomal protein S6 kinase; PE, preeclampsia; LB, labyrinth; SP, spongiotrophoblast.

fibrosis and increased decidual fibrous necrosis. Therefore, the proliferation and differentiation of placental cytotrophoblasts were inhibited in the PE rats.

\section{E-BP1,p70S6K and mTOR are downregulated in PE placental} tissues. Immunohistochemical staining was performed to measure the positive expression rates of the 4E-BP1, p70S6K and $\mathrm{mTOR}$ proteins in placental tissues from the normal and $\mathrm{PE}$ rats. The immunohistochemical staining (Fig. 2A-D) showed that the $4 \mathrm{E}-\mathrm{BP} 1, \mathrm{p} 70 \mathrm{~S} 6 \mathrm{~K}$ and mTOR proteins were mainly expressed in the cytoplasm and that the positive cells were light yellow, tan or tan brown in color. Compared with that in the normal rats, positive expression of the 4E-BP1, p70S6K and mTOR proteins was evidently reduced in the placental tissues from the $\mathrm{PE}$ rats $(\mathrm{P}<0.05)$. These data revealed that the mTOR signaling pathway was inactivated in the placental tissues of the PE rats.

GNG7 is upregulated and the mTOR signaling pathway is inactivated in PE rats. RT-qPCR and western blot analyses were conducted to detect the mRNA and protein expression levels of GNG7 and mTOR signaling pathway-related genes in the normal and PE rats; the results are shown in Fig. 3A-C. In contrast to those of the normal rats, the mRNA and protein levels of 4E-BP1, p70S6K, mTOR, VEGF, TGF- $\beta 1$, AP- $2 \gamma$ and $\mathrm{Bcl}-2$, and the extent of 4E-BP1, p70S6K and mTOR phosphorylation were significantly decreased in the placental tissues of the PE rats, whereas the $\mathrm{mRNA}$ and protein expression levels of GNG7, AP- $2 \alpha$ and Bax were elevated (all $\mathrm{P}<0.05$ ). These results showed that GNG7 was expressed at high levels in the placental tissues of the PE rats and that mTOR signaling pathway activation was inhibited in PE.
GNG7 silencing activates the mTOR signaling pathway to enhance proliferation and differentiation and suppress apoptosis of placental cytotrophoblasts in PE rats. To analyze the effects of GNG7 silencing on the proliferation, differentiation and apoptosis of placental cytotrophoblasts in the PE rats, RT-qPCR and western blot analyses were performed to examine the mRNA and protein levels of GNG7, mTOR signaling pathway-related factors (4E-BP1, p70S6K and mTOR), cell proliferation-related factors (VEGF and TGF- $\beta 1$ ), cell differentiation-related factors (AP-2 $\alpha$ and AP- $2 \gamma$ ) and cell apoptosis-related factors (Bax and $\mathrm{Bcl}-2$ ); the results are shown in Fig. 4A-E. Compared with those of the normal group, the mRNA and protein levels of 4E-BP1, p70S6K, mTOR, VEGF, TGF- $\beta 1$, AP- $2 \gamma$ and Bcl-2 and the extent of 4E-BP1, p70S6K and mTOR phosphorylation were markedly decreased in the remaining five groups, whereas the $\mathrm{mRNA}$ and protein levels of GNG7, AP-2 $\alpha$ and Bax were notably increased (all $\mathrm{P}<0.05$ ). No significant difference was found in the expression of these genes between the blank and NC groups ( $\mathrm{P}>0.05)$. Compared with the blank and NC groups, the GNG7-siRNA,HIV-1 Tat and GNG7-siRNA + HIV-1 Tat groups exhibited elevated mRNA and protein levels 4E-BP1, p70S6K, mTOR, VEGF, TGF- $\beta 1$, AP- $2 \gamma$ and Bcl-2, and phosphorylation of 4E-BP1, p70S6K and mTOR, but reduced mRNA and protein levels of AP- $2 \alpha$ and Bax (all $\mathrm{P}<0.05)$. The mRNA and protein levels of GNG7 in the GNG7-siRNA and GNG7-siRNA + HIV-1 Tat groups were markedly decreased compared with those in the blank and $\mathrm{NC}$ groups (all $\mathrm{P}<0.05$ ). Compared with the GNG7-siRNA and HIV-1 Tat groups, the GNG7-siRNA + HIV-1 Tat group presented with increased mRNA and protein levels 4E-BP1, p70S6K, mTOR, VEGF, TGF- $\beta 1$, AP- $2 \gamma$ and Bcl-2, and phosphorylation of 4E-BP1, p70S6K and mTOR, but decreased 

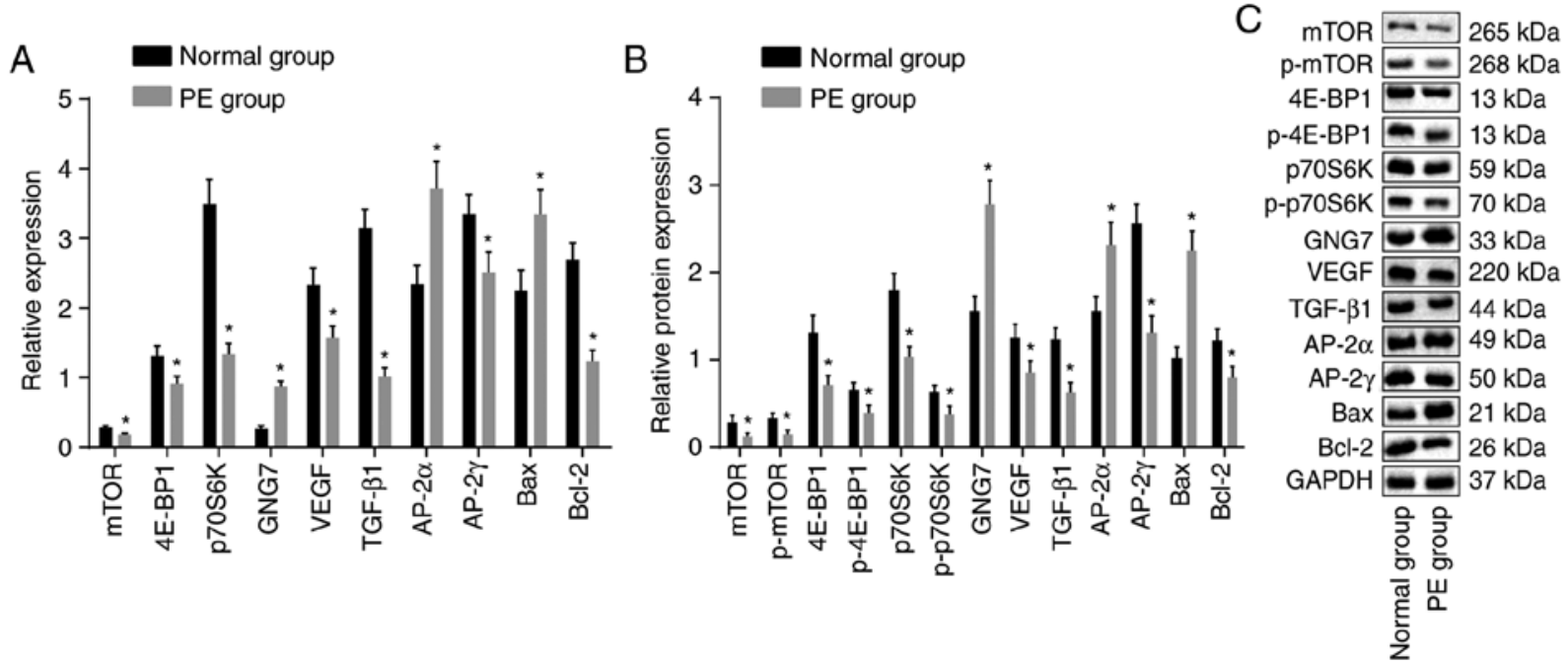

Figure 3. GNG7 is expressed at a high level in placental tissues of PE rats and mTOR signaling pathway activation is suppressed. (A) mRNA expression of 4E-BP1, p70S6K, mTOR, VEGF, TGF- $\beta 1$, AP- $2 \gamma$, Bcl-2, GNG7, AP-2 $\alpha$ and Bax in the PE rats, determined by reverse transcription-quantitative polymerase chain reaction analysis. (B) Protein levels of 4E-BP1, p70S6K, mTOR, VEGF, TGF- $\beta 1$, AP- $2 \gamma$, Bcl-2, GNG7, AP-2 $\alpha$ and Bax, and the extent of 4E-BP1, p70S6K and mTOR phosphorylation in the PE rats were measured from (C) blots obtained by western blot analysis. "P<0.05, compared with the normal group. The mRNA and protein level measurement data are expressed as the mean \pm standard deviation and were analyzed with an unpaired t-test. The sample sizes of the normal and PE groups were 10 and 12, respectively. PE, preeclampsia; GNG7, G protein $\gamma$ 7; 4E-BP1, 4E-binding protein 1; p70S6K, phosphoprotein 70 ribosomal protein S6 kinase; mTOR, mammalian target of rapamycin; VEGF, vascular endothelial growth factor; TGF- $\beta 1$, transforming growth factor- $\beta 1$; AP- $2 \gamma$, activator protein- $2 \gamma$; AP- $2 \alpha$, activator protein-2 $\alpha$; Bcl-2, B-cell lymphoma 2; Bax, Bcl-2-associated X protein; GAPDH, glyceraldehyde-3-phosphate dehydrogenase; p-, phosphorylated.
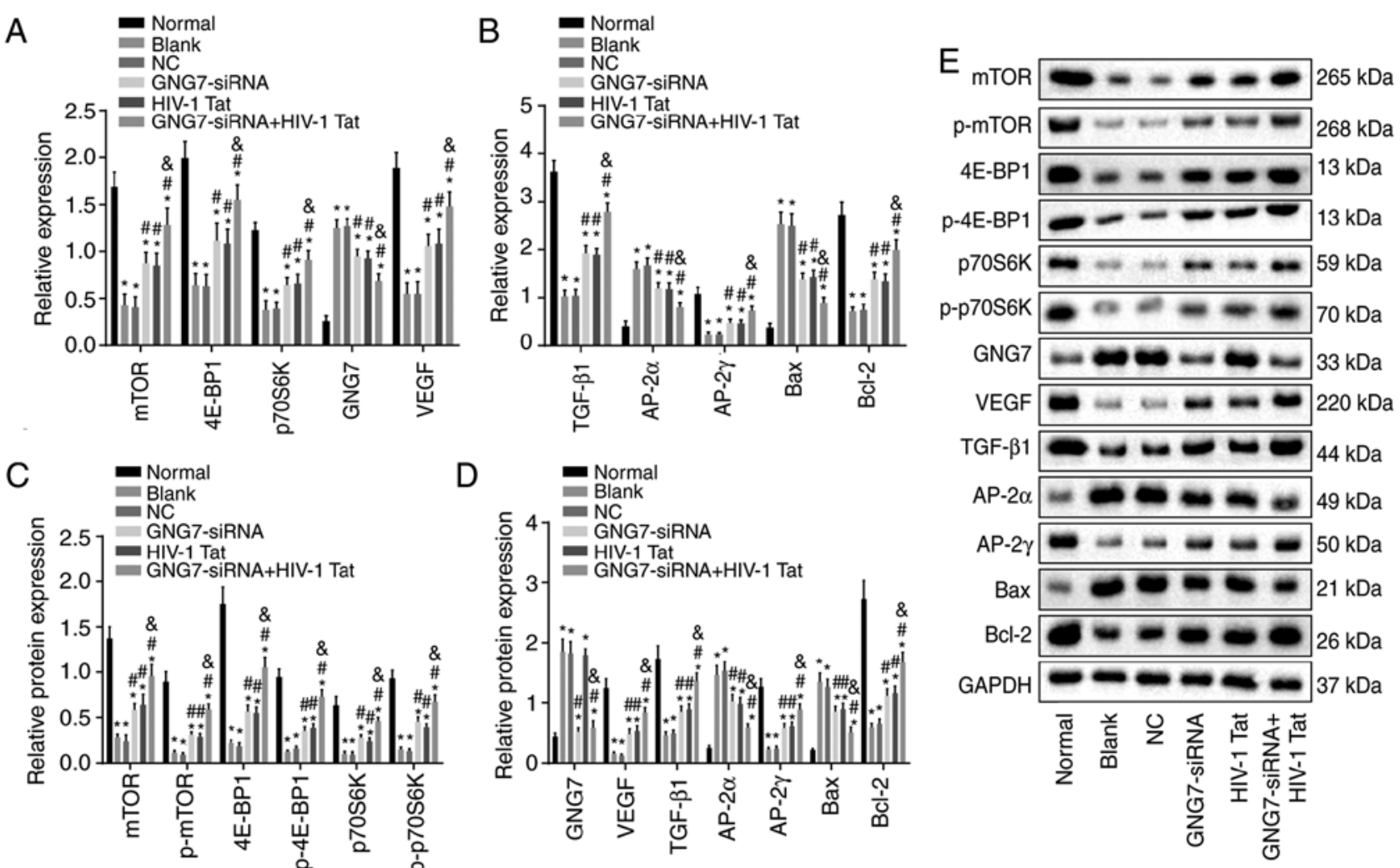

Figure 4. GNG7 silencing activates the mTOR signaling pathway, promotes the proliferation and differentiation of placental cytotrophoblasts in PE rats and inhibits apoptosis. mRNA expression levels of (A) mTOR, 4E-BP1, p70S6K, GNG7, VEGF and (B) TGF- $\beta 1$, AP- $2 \gamma$, AP- $2 \alpha$, Bcl-2 and Bax were determined in the PE rats in response to GNG7-siRNA or HIV-1 Tat treatment or GNG7-siRNA and HIV-1 Tat cotreatment by reverse transcription-quantitative polymerase chain reaction analysis. (C) Protein levels of mTOR, 4E-BP1 and p70S6K, extent of 4E-BP1, p70S6K and mTOR phosphorylation and (D) protein levels of GNG7, VEGF, TGF- $\beta 1$, AP- $2 \gamma$, AP-2 $\alpha$, Bcl-2 and Bax were determined in the PE rats in response to GNG7-siRNA or HIV-1 Tat treatment or GNG7-siRNA and HIV-1 Tat cotreatment by western blotting. (E) Protein levels of 4E-BP1, p70S6K, mTOR, VEGF, TGF- $\beta 1$, AP-2 $\gamma$, Bcl-2, GNG7, AP-2 $\alpha$ and Bax, p-4E-BP1, p-p70S6K and p-mTOR. "P<0.05 compared with the normal group; ${ }^{\mathrm{P}} \mathrm{P}<0.05$ compared with the blank and NC groups; ${ }^{\circledR} \mathrm{P}<0.05$ compared with the GNG7-siRNA and HIV-1 Tat groups. The measurement data are expressed as the mean \pm standard deviation and were analyzed by one-way analysis of variance. The experiment was repeated three times; PE, preeclampsia; GNG7, G protein $\gamma$ 7; 4E-BP1, 4E-binding protein 1; p70S6K, phosphoprotein 70 ribosomal protein S6 kinase; mTOR, mammalian target of rapamycin; VEGF, vascular endothelial growth factor; TGF- $\beta 1$, transforming growth factor- $\beta 1$; AP- $2 \gamma$, activator protein- $2 \gamma$; AP-2 $\alpha$, activator protein-2 $\alpha$; Bcl-2, B-cell lymphoma 2 ; Bax, Bcl-2-associated X protein; GAPDH, glyceraldehyde-3-phosphate dehydrogenase; p-, phosphorylated; siRNA, small interfering RNA; NC, negative control. 

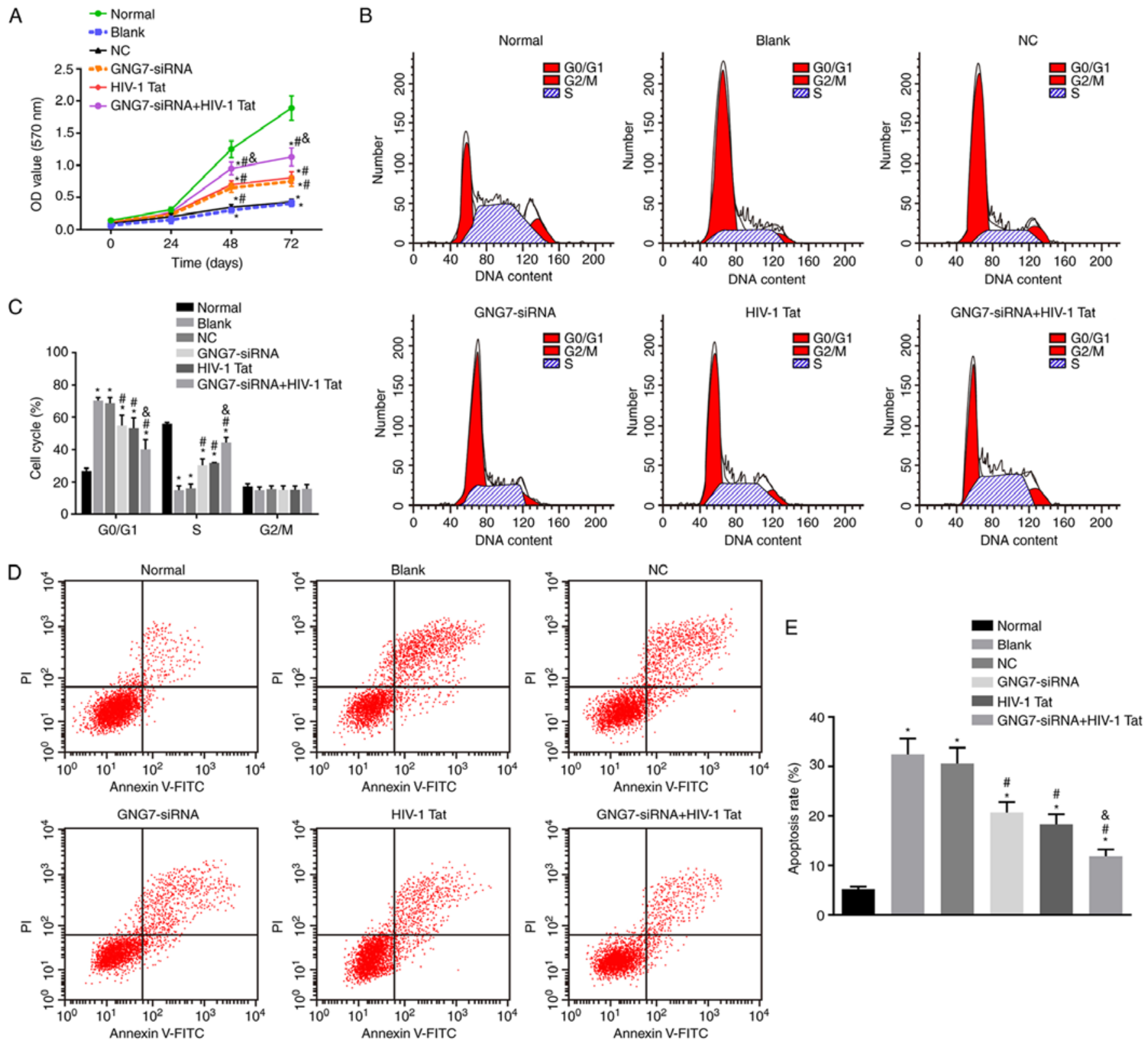

Figure 5. Silencing GNG7 promotes cell proliferation and represses apoptosis of placental cytotrophoblasts of PE rats. (A) Cell proliferation in response to GNG7-siRNA or HIV-1 Tat treatment or GNG7-siRNA and HIV-1 Tat cotreatment as measured using a 3-(4,5-dimethyl-2-thiazolyl)-2,5-diphenyl-2-H-tetrazolium bromide assay. (B) Results of flow cytometry used to determine (C) cell cycle distribution in response to GNG7-siRNA or HIV-1 Tat treatment or GNG7-siRNA and HIV-1 Tat cotreatment. (D) Cell apoptosis in response to GNG7-siRNA or HIV-1 Tat treatment or GNG7-siRNA and HIV-1 Tat cotreatment as measured by flow cytometry. ${ }^{*} \mathrm{P}<0.05$ compared with the normal group; ${ }^{\#} \mathrm{P}<0.05$ compared with the blank and $\mathrm{NC}$ groups; ${ }^{\star} \mathrm{P}<0.05$ compared with the GNG7-siRNA and HIV-1 Tat groups. The measurement data are expressed as the mean \pm standard deviation; data in panels A and C were analyzed by two-way ANOVA, and data in panel E were analyzed by one-way ANOVA. The experiment was repeated 3 times; GNG7, G protein $\gamma 7$; NC, negative control; siRNA, small interfering RNA; ANOVA, analysis of variance; OD, optical density; PI, propidium iodide.

mRNA and protein levels AP-2 $\alpha$ and Bax (all P<0.05). These results suggested that silencing the expression of GNG7 led to enhanced proliferation and differentiation of placental cytotrophoblasts in the PE rats, but reduced apoptosis, via activation of the mTOR signaling pathway.

GNG7 silencing promotes placental cytotrophoblast proliferation and differentiation and inhibits apoptosis in PE rats. Placental cytotrophoblasts from the six groups were inoculated into a 96-well plate, and their viability was observed using an MTT assay to investigate the ability of GNG7 to affect the biological function of placental cytotrophoblasts. The results
(Fig. 5A) demonstrated that, $24 \mathrm{~h}$ following the respective treatments, no significant difference was present in the viability of the placental cytotrophoblasts in each group (all $\mathrm{P}>0.05$ ). However, cell viability was decreased over time in the cytotrophoblasts isolated from the PE rats without treatment, those treated with the empty plasmid, GNG7-siRNA or HIV-1 Tat and those cotreated with GNG7-siRNA and HIV-1 Tat compared with that of the cytotrophoblasts isolated from the normal rats $(\mathrm{P}<0.05)$. Compared with the cytotrophoblasts without treatment or those treated with the empty plasmid, the viability of placental trophoblasts was increased significantly in the cytotrophoblasts treated with GNG7-siRNA or HIV-1 Tat and those cotreated 

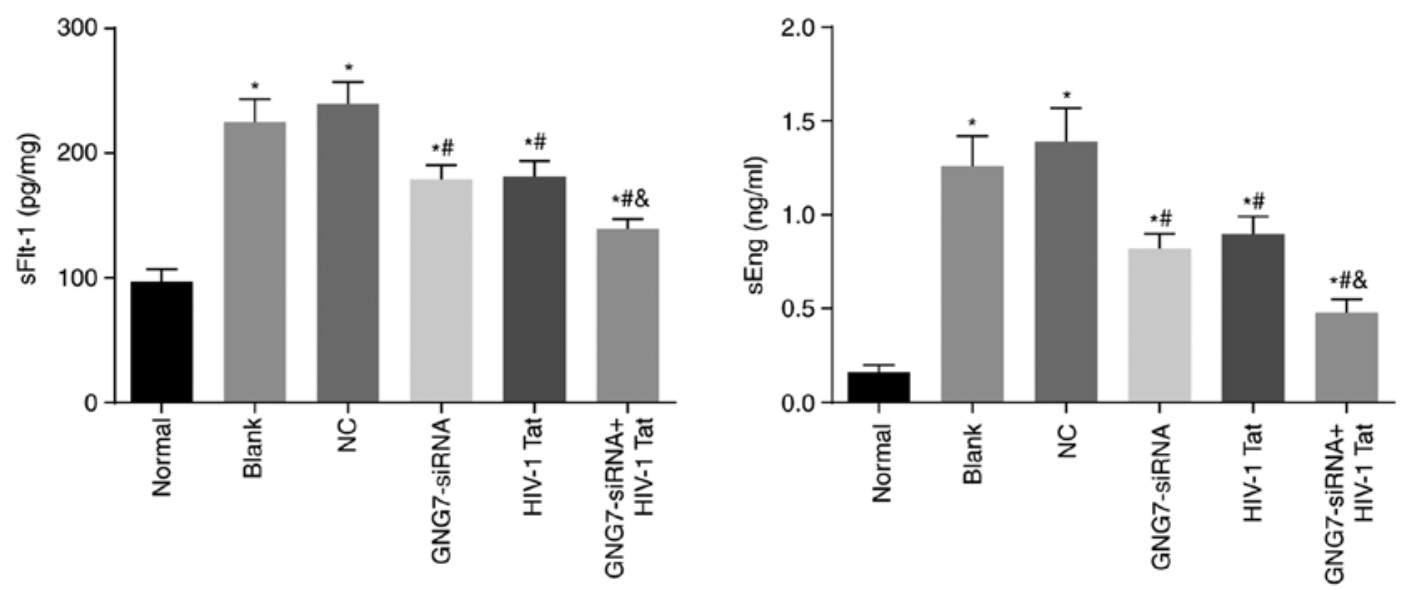

Figure 6. GNG7 gene silencing inhibits the expression of sFlt-1 and sEng. "P $<0.05$ compared with the normal group; ${ }^{\text {P }}<0.05$ compared with the blank and NC groups; ${ }^{\circledR} \mathrm{P}<0.05$ compared with the GNG7-siRNA and HIV-1 Tat groups. The measurement data are expressed as the mean \pm standard deviation and were analyzed by one-way analysis of variance. The experiment was repeated three times. sFlt-1, soluble fms-like tyrosine kinase 1; sEng, soluble endoglin; GNG7, G protein $\gamma$ 7; NC, negative control; siRNA, small interfering RNA.

with GNG7-siRNA and HIV-1 Tat $(\mathrm{P}<0.05)$. GNG7-siRNA and HIV-1 Tat cotreatment resulted in higher cytotrophoblast viability compared with treatment with either alone $(\mathrm{P}<0.05)$. Taken together, these results show that the suppression of GNG7 enhanced placental cytotrophoblast proliferation.

Subsequently, PI staining was performed to assess the cell cycle distribution. The PI staining results (Fig. 5B and C) showed that an increased cell proportion in $\mathrm{G}_{0} / \mathrm{G}_{1}$ phase and a decreased cell proportion in $\mathrm{S}$ phase were the main cell cycle changes of the cytotrophoblasts isolated from the PE rats without treatment, those treated with the empty plasmid, GNG7-siRNA or HIV-1 Tat, and those cotreated with GNG7-siRNA and HIV-1 Tat compared with those of the cytotrophoblasts isolated from the normal rats (all $\mathrm{P}<0.05)$. However, compared with the untreated cytotrophoblasts or those treated with the empty plasmid, the cytotrophoblasts treated with the GNG7-siRNA or HIV-1 Tat and those cotreated with GNG7-siRNA and HIV-1 Tat exhibited decreased cell arrest in the $\mathrm{G}_{0} / \mathrm{G}_{1}$ phase and increased cells in $\mathrm{S}$ phase (all $\mathrm{P}<0.05$ ). GNG7-siRNA and HIV-1 Tat cotreatment led to a reduced proportion of cells in the $G_{0} / G_{1}$ phase and an elevated proportion in the $\mathrm{S}$ phase compared with the cells exposed to either treatment alone (all $\mathrm{P}<0.05$ ). Therefore, GNG7 gene silencing induced cell cycle progression of the placental cytotrophoblasts in the PE rats.

Flow cytometric analysis, performed to evaluate apoptosis of placental cytotrophoblast cells (Fig. 5D and E) showed increased apoptotic rates in the untreated cytotrophoblasts, those treated with the empty plasmid, GNG7-siRNA or HIV-1 Tat, and those cotreated with GNG7-siRNA and HIV-1 Tat compared with the rate in cytotrophoblasts isolated from the normal rats (all $\mathrm{P}<0.05)$. The GNG7-siRNA and HIV-1 Tat treatments and GNG7-siRNA and HIV-1 Tat cotreatment resulted in decreased cell apoptosis (all $\mathrm{P}<0.05)$. Compared with GNG7-siRNA or HIV-1 Tat treatment, cell apoptosis was decreased by GNG7-siRNA and HIV-1 Tat cotreatment (all $\mathrm{P}<0.05$ ). Therefore, GNG7 gene silencing inhibited cell apoptosis in the placental cytotrophoblasts of the PE rats.

GNG7 depletion inhibits sFlt-1 and sEng levels in PE rats. ELISA was conducted to measure the sFlt-1 and sEng levels in the supernatants of placental cytotrophoblasts subjected to different treatments. The results (Fig. 6) showed elevated sFlt-1 and sEng levels in cytotrophoblasts isolated from the $\mathrm{PE}$ rats without treatment, those treated with the empty plasmid, GNG7-siRNA or HIV-1 Tat, and those cotreated with GNG7-siRNA and HIV-1 Tat compared with those in cytotrophoblasts isolated from the normal rats (all $\mathrm{P}<0.05)$. The cytotrophoblasts treated with GNG7-siRNA or HIV-1 Tat and those cotreated with GNG7-siRNA and HIV-1 Tat exhibited decreased levels of sFlt-1 and sEng (all P<0.05). GNG7-siRNA and HIV-1 Tat cotreatment contributed to further reduction of the levels of sFlt-1 and sEng compared with those of either treatment alone (all $\mathrm{P}<0.05$ ). Therefore, GNG7 gene silencing suppressed the levels of sFlt-1 and sEng in the placental cytotrophoblasts of the PE rats.

GNG7 knockdown enhances cell proliferation and differentiation and represses apoptosis in placental cytotrophoblasts from $P E$ rats through activation of the $m T O R$ signaling pathway. To further examine whether GNG7 was associated with enhanced cell proliferation and differentiation and inhibition of apoptosis in placental cytotrophoblasts from PE rats through regulation of the mTOR signaling pathway, the cytotrophoblasts were cotransfected with GNG7-siRNA and rapamycin (mTOR inhibitor); cells treated with GNG7-siRNA and DMSO served as a control. Compared with those of the cells cotreated with GNG7-siRNA and DMSO, the mTOR signaling pathway-related protein levels were decreased by GNG7-siRNA and rapamycin cotreatment (Fig. 7A). Cell proliferation (Fig. 7B) and cell cycle arrest (Fig. 7C) were reduced, whereas cell apoptosis (Fig. 7D) was accelerated by GNG7-siRNA and rapamycin cotreatment. These results demonstrated that GNG7 silencing activated the mTOR signaling pathway, which promoted cell proliferation and differentiation and inhibited apoptosis of the placental cytotrophoblasts from the PE rats.

\section{Discussion}

$\mathrm{PE}$ is a serious pregnancy-specific disease that is associated with increased morbidity and mortality rates of the mother 

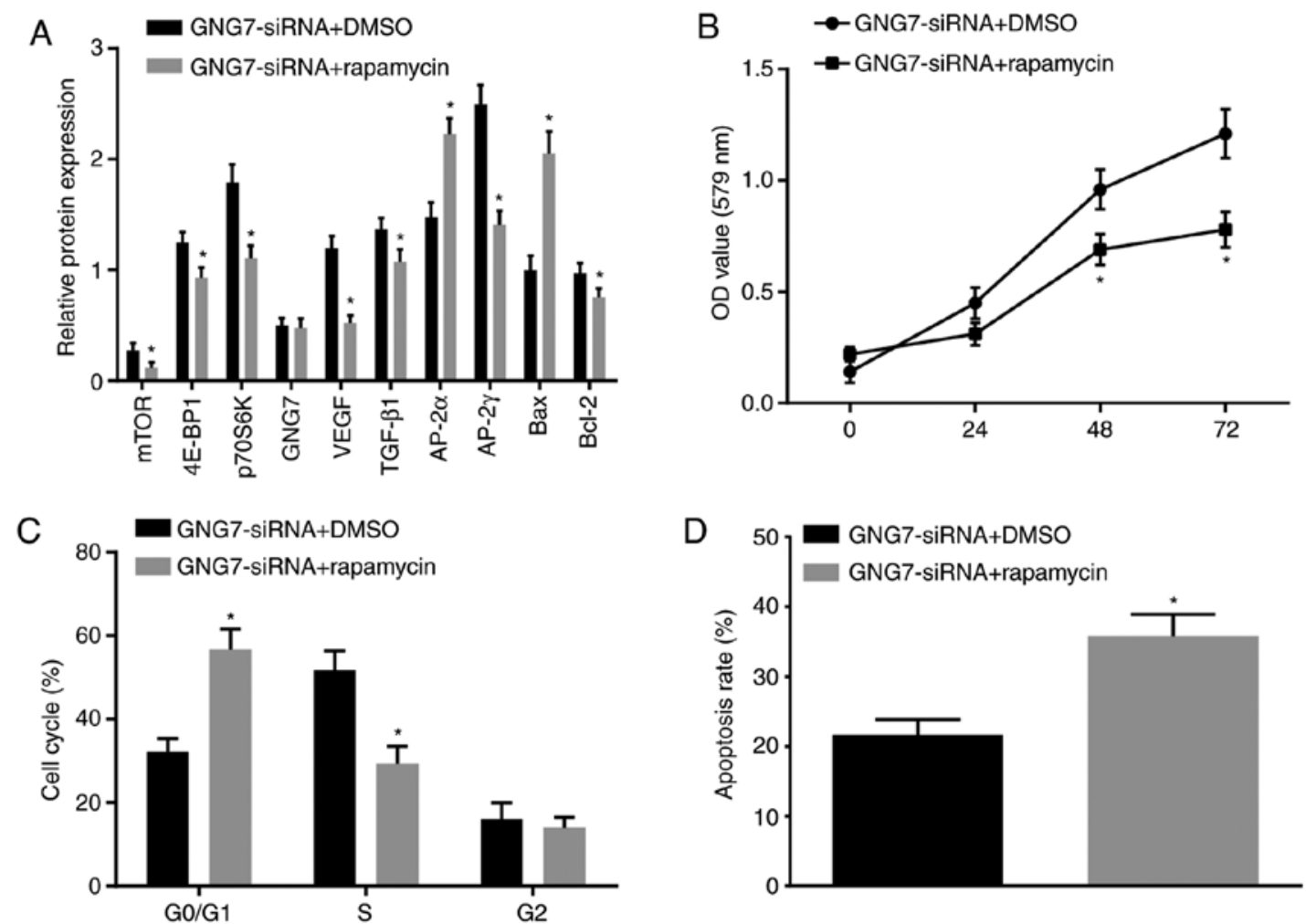

Figure 7. GNG7 depletion enhances cell proliferation and restrains apoptosis in placental cytotrophoblasts of PE rats through activating the mTOR signaling pathway. (A) Protein levels of, 4E-BP1, p70S6K, mTOR, VEGF, TGF- $\beta 1$, AP- $2 \gamma, \mathrm{Bcl}-2$, GNG7, AP- $2 \alpha$ and Bax in PE rats in response to cotreatment with GNG7-siRNA and DMSO or rapamycin, as measured by western blotting. (B) Cell proliferation in response to cotreatment with GNG7-siRNA and DMSO or rapamycin, as detected by the 3-(4,5-dimethyl-2-thiazolyl)-2,5-diphenyl-2-H-tetrazolium bromide assay. (C) Cell cycle distribution in response to cotreatment with GNG7-siRNA and DMSO or rapamycin, as detected by flow cytometry. (D) Cell apoptosis in response to cotreatment with GNG7-siRNA and DMSO or rapamycin, as assessed by flow cytometry. The test results are measurement data expressed as the mean \pm standard deviation and analyzed by an independent sample t-test. The experiment was repeated three times. "P<0.05 compared with the GNG7-siRNA + DMSO group. GNG7, G protein $\gamma 7$ 7; 4E-BP1, 4E-binding protein 1; p70S6K, phosphoprotein 70 ribosomal protein S6 kinase; mTOR, mammalian target of rapamycin; VEGF, vascular endothelial growth factor; TGF- $\beta 1$, transforming growth factor $\beta 1$; AP- $2 \gamma$, activator protein- $2 \gamma$; AP-2 $\alpha$, activator protein-2 $\alpha$; Bcl-2, B-cell lymphoma 2 ; Bax, Bcl-2-associated X protein; NC, negative control; siRNA, small interfering RNA; DMSO, dimethylsulfoxide; OD, optical density.

and the neonate (17). Human extravillous trophoblast invasion is implicated in inadequate arterial remodeling, resulting in a severe pregnancy disorder even for early-onset PE (18). The present study mainly examined the mechanism underlying how GNG7 affects the proliferation, differentiation and apoptosis of placental cytotrophoblasts in PE model rats through activation of the mTOR signaling pathway. The findings provide evidence that GNG7 gene silencing enhances the proliferation and differentiation of placental cytotrophoblasts in PE rats via activation of the mTOR signaling pathway.

In the present study, weak expression of mTOR and a higher expression of GNG7 were found in the placental tissues and cytotrophoblasts from the PE rats. Although loss of GNG7 has been implicated in human cancer, including head and neck cancer (7) and extrahepatic cholangiocarcinoma (19), the expression of GNG7 in PE remains unclear. In the present study, GNG7 was elevated in the PE rats. Functionally, mTOR acts as a connector of growth factor signals to energy status and nutrient levels, thereby modulating protein metabolism and cell growth (20). Unlike amino acid transport proteins, the increase in the expression of mTOR is unique to intrauterine growth restriction-associated pregnancy and is not observed in PE (21). The data obtained in the present study showed decreased expression of 4E-BP1 and p70S6K in PE rat placental tissues, which was indicative of inactivation of the mTOR signaling pathway in PE.
To further analyze the potential effects of GNG7, placental cytotrophoblasts isolated from normal and $\mathrm{PE}$ rats were treated with an siRNA against GNG7 (GNG7-siRNA) and/or an mTOR signaling pathway activator (HIV-1 Tat). The results showed that the suppression of GNG7 activated the mTOR signaling pathway to promote the proliferation and inhibit the apoptosis of cytotrophoblasts in PE rats. Activation of the mTOR signaling pathway has been shown to promote the proliferation of invasive pituitary adenoma cells (22). In addition, the mTOR signaling pathway has been shown to be involved in the proliferation and apoptosis of glioma cells (23). GNG7 gene silencing and mTOR signaling pathway activation resulted in elevated mRNA and protein levels of VEGF, TGF- $\beta 1$, AP- $2 \gamma$ and $\mathrm{Bcl}-2$, but reduced mRNA and protein levels of AP- $2 \alpha$ and Bax, which further suggested its promoting effect on cell proliferation and differentiation and its inhibitory effect on apoptosis. The AP-2 protein family includes five transcription factors $(\alpha, \beta, \gamma, \delta$ and $\varepsilon)$, which are involved in embryonic development (24). As a sequence-specific DNA-binding transcription factor, AP- $2 \alpha$ is implicated in cell transformation and differentiation and positively affects the EGF-dependent invasion of human trophoblasts (25). The regulation of Bcl-2 and Bax mediated by AP- $2 \alpha$ has been demonstrated to influence cell apoptosis, which in turn results in PE pathogenesis (26). The Bcl-2 and Bax proteins belong to the Bcl-2 family, have 
opposing functions and are involved in the pathological process of PE under regulation by Ap- $2 \alpha$; elevation of the Bcl-2 protein usually indicates an increased anti-apoptotic function of cells, whereas elevation of the Bax protein indicates a promotion of cell apoptosis (27). There is evidence that the elevated expression of AP- $2 \gamma$ exerts a protective effect against $\mathrm{PE}$, thereby avoiding the increase in BP (28). p70S6K, which is a downstream target of mTOR, acts as a protein synthesis regulator in cell growth and proliferation (29). VEGF has been shown to enhance neovascularization in animals and human subjects, and its deficiency in PE is attributed to the lower angiogenic capacity of the fetal endothelium $(30,31)$. GNG7 gene silencing resulted in elevated expression and phosphorylation of 4E-BP1, p70S6K and mTOR, thus inducing activation of the mTOR signaling pathway.

Typically, PE is characterized by hypertensive disorder in pregnancy, proteinuria and dysfunctions in other maternal organs and tissues (32). Pregnancy-induced hypertension is a particular complication during the gestation period, which refers to pre-existing hypertension, gestational hypertension and PE (33). Additionally, the overexpression of sFlt-1 has been reported to induce hypertension to limit fetal growth and provide support for the pathogenesis of PE (34). Maynard et al first reported the association between sFlt-1 and PE in 2003 and showed that the level of sFlt-1 was markedly increased in patients with PE (35). Another study revealed that the level of sFlt-1 showed an increased tendency with the deterioration of PE, which induced alterations of cytotrophoblast cell morphology and function (36). Consistently, increased expression levels of sFlt-1 and sEng were detected in the cytotrophoblasts of PE rats in the present study. sEng is a homodimeric membrane glycoprotein that is expressed in vascular endothelial cells and serves as a cell surface coreceptor for TGF- $\beta 1$, which affects vascular homeostasis. Venkatesha et al found that placenta-secreted sEng was a type of angiogenesis inhibitor, which induced vascular damage through regulating TGF- $\beta 1$ (37). The present study found that GNG7 gene silencing contributed to reduced levels of sFlt-1 and sEng in cytotrophoblasts, thus alleviating disorders in the PE rats.

Consequently, the present study found that GNG7 gene silencing inhibited cell apoptosis and promoted the proliferation and differentiation of placental cytotrophoblasts in PE rats by activating the mTOR signaling pathway. GNG7 was expressed at a high level and the mTOR signaling pathway was inhibited during PE, resulting in vascular endothelial dysfunction and placental hypoxia. Inadequate trophoblastic invasion, inhibition of proliferation and enhanced apoptosis of cytotrophoblasts were found in the PE rats, which aggravated PE. By contrast, GNG7 gene silencing reduced the restriction on the mTOR signaling pathway and promoted the proliferation and differentiation of cytotrophoblasts in the PE rats. Therefore, GNG7 can be suggested as a novel target for PE treatment. Further investigation of the molecular mechanisms of GNG7-targeted PE therapeutic methods is warranted. Additionally, further efforts are expected to examine the clinical efficacy of potential targeted therapy for patients with PE. Although pregnancy-induced hypertension has the same clinical outcomes as PE, the pathogenesis differs. Therefore, determining whether a similar influence exists requires further investigation.

\section{Acknowledgements}

Not applicable.

\section{Funding}

No funding was received.

\section{Availability of data and materials}

The datasets used and/or analyzed during the current study are available from the corresponding author on reasonable request.

\section{Authors' contributions}

WSL and YLD designed the study. WSL and YLD collated the data, designed and developed the database, performed data analyses and produced the initial draft of the manuscript. WSL and YLD contributed to drafting the manuscript. Both authors contributed to the revised manuscript and have read and approved the final submitted manuscript.

\section{Ethics approval and consent to participate}

The present study was conducted in strict accordance with the recommendations in the Guide for the Care and Use of Laboratory Animals of the National Institutes of Health. The protocol was approved by the Institutional Animal Care and Use Committee of Second Xiangya Hospital, Central South University (Changsha, China).

\section{Patient consent for publication}

Not applicable.

\section{Competing interests}

The authors declare that they have no competing interests.

\section{References}

1. Ghulmiyyah L and Sibai B: Maternal mortality from preeclampsia/eclampsia. Semin Perinatol 36: 56-59, 2012.

2. Phipps E, Prasanna D, Brima W and Jim B: Preeclampsia: Updates in pathogenesis, definitions, and guidelines. Clin J Am Soc Nephrol 11: 1102-1113, 2016.

3. Staff AC, Benton SJ, von Dadelszen P, Roberts JM, Taylor RN, Powers RW, Charnock-Jones DC and Redman CW: Redefining preeclampsia using placenta-derived biomarkers. Hypertension 61: 932-942, 2013.

4. Burwick RM and Feinberg BB: Eculizumab for the treatment of preeclampsia/HELLP syndrome. Placenta 34: 201-203, 2013.

5. Hansson SR, Gram M and Akerstrom B: Fetal hemoglobin in preeclampsia: A new causative factor, a tool for prediction/diagnosis and a potential target for therapy. Curr Opin Obstet Gynecol 25: 448-455, 2013.

6. Liu J, Ji X, Li Z, Yang X, Wang W and Zhang X: G protein gamma subunit 7 induces autophagy and inhibits cell division. Oncotarget 7: 24832-24847, 2016.

7. Hartmann S, Szaumkessel M, Salaverria I, Simon R, Sauter G, Kiwerska K, Gawecki W, Bodnar M, Marszalek A, Richter J, et al: Loss of protein expression and recurrent DNA hypermethylation of the GNG7 gene in squamous cell carcinoma of the head and neck. J Appl Genet 53: 167-174, 2012. 
8. Kvehaugen AS, Melien O, Holmen OL, Laivuori H, Oian P, Andersgaard AB, Dechend R and Staff AC: Single nucleotide polymorphisms in $\mathrm{G}$ protein signaling pathway genes in preeclampsia. Hypertension 61: 655-661, 2013.

9. Populo H, Lopes JM and Soares P: The mTOR signalling pathway in human cancer. Int J Mol Sci 13: 1886-1918, 2012.

10. Gomez-Pinillos A and Ferrari AC: mTOR signaling pathway and mTOR inhibitors in cancer therapy. Hematol Oncol Clin North Am 26: 483-505, 2012.

11. Zeng $X$, Huang $Z$, Mao $X$, Wang $J, W u ~ G$ and Qiao $S$ $\mathrm{N}$-carbamylglutamate enhances pregnancy outcome in rats through activation of the $\mathrm{PI} 3 \mathrm{~K} / \mathrm{PKB} / \mathrm{mTOR}$ signaling pathway. PLoS One 7: e41192, 2012.

12. Wu D, Hong H, Huang X, Huang L, He Z, Fang Q and Luo Y: CXCR2 is decreased in preeclamptic placentas and promotes human trophoblast invasion through the Akt signaling pathway. Placenta 43: 17-25, 2016.

13. Amaral LM, Cornelius DC, Harmon A, Moseley J, Martin JN Jr and LaMarca B: 17-hydroxyprogesterone caproate significantly improves clinical characteristics of preeclampsia in the reduced uterine perfusion pressure rat model. Hypertension 65: 225-231, 2015.

14. Serman L, Vlahovic M, Sijan M, Bulic-Jakus F, Serman A, Sincic N, Matijevic R, Juric-Lekic G and Katusic A: The impact of 5-azacytidine on placental weight, glycoprotein pattern and proliferating cell nuclear antigen expression in rat placenta. Placenta 28: 803-811, 2007.

15. Livak KJ and Schmittgen TD: Analysis of relative gene expression data using real-time quantitative PCR and the 2(-Delta Delta C(T)) method. Methods 25: 402-408, 2001

16. Bergmann A, Ahmad S, Cudmore M, Gruber AD, Wittschen P, Lindenmaier W, Christofori G, Gross V, Gonzalves ACh, Grone HJ, et al: Reduction of circulating soluble Flt-1 alleviates preeclampsia-like symptoms in a mouse model. J Cell Mol Med 14: 1857-1867, 2010.

17. Grotegut CA: Prevention of preeclampsia. J Clin Invest 126: 4396-4398, 2016.

18. Velicky P, Windsperger K, Petroczi K, Pils S, Reiter B, Weiss T, Vondra S, Ristl R, Dekan S, Fiala C, et al: Pregnancy-associated diamine oxidase originates from extravillous trophoblasts and is decreased in early-onset preeclampsia. Sci Rep 8: 6342, 2018.

19. Wang M, Gong B, Li Y and Wang Y: Human G-protein gamma 7 in extrahepatic cholangiocarcinoma and its clinicopathological significance. Hematol Oncol Stem Cell Ther 3: 66-70, 2010

20. Giguere V: Canonical signaling and nuclear activity of mTOR-a teamwork effort to regulate metabolism and cell growth. FEBS J 285: 1572-1588, 2018.

21. Aiko Y, Askew DJ, Aramaki S, Myoga M, Tomonaga C Hachisuga T, Suga R, Kawamoto T, Tsuji M and Shibata E: Differential levels of amino acid transporters System L and ASCT2, and the mTOR protein in placenta of preeclampsia and IUGR. BMC Pregnancy Childbirth 14: 181, 2014.

22. Zhou K, Fan YD, Wu PF, Duysenbi S, Feng ZH, Du GJ and Zhang TR: MicroRNA-145 inhibits the activation of the mTOR signaling pathway to suppress the proliferation and invasion of invasive pituitary adenoma cells by targeting AKT3 in vivo and in vitro. Onco Targets Ther 10: 1625-1635, 2017.

23. Wang G, Liu M, Wang H, Yu S, Jiang Z, Sun J, Han K, Shen J, Zhu M, Lin Z, et al: Centrosomal protein of 55 regulates glucose metabolism, proliferation and apoptosis of glioma cells via the Akt/mTOR signaling pathway. J Cancer 7: 1431-1440, 2016.

24. Orso F, Penna E, Cimino D, Astanina E, Maione F, Valdembri D, Giraudo E, Serini G, Sismondi P, De Bortoli M and Taverna D: AP-2alpha and AP-2gamma regulate tumor progression via specific genetic programs. FASEB J 22: 2702-2714, 2008.
25. Biadasiewicz K, Sonderegger S, Haslinger P, Haider S, Saleh L, Fiala C, Pollheimer J and Knofler M: Transcription factor AP-2 $\alpha$ promotes EGF-dependent invasion of human trophoblast. Endocrinology 152: 1458-1469, 2011

26. Zhang L, Jia L, Cui S, Shi Y, Chang A, Wang P and Zhang Z: AP-2alpha-dependent regulation of Bcl-2/Bax expression affects apoptosis in the trophoblast. J Mol Histol 43: 681-689, 2012.

27. Wang A, Liu Q, Zhang J and Zheng R: Berberine alleviates preeclampsia possibly by regulating the expression of interleukin-2/interleukin-10 and Bcl-2/Bax. Int J Clin Exp Med 8: 16301-16307, 2015.

28. Schneider HA, Gembruch U, Fimmers R, Schmitz J and Muller AM: Expression of AP- $2 \gamma$ in placentas of patients with preeclampsia and of smokers. Arch Gynecol Obstet 291: 1015-1021, 2015

29. Hu LY, Sun ZG, Wen YM, Cheng GZ, Wang SL, Zhao HB and Zhang XR: ATP-mediated protein kinase B Akt/mammalian target of rapamycin mTOR/p70 ribosomal S6 protein p70S6 kinase signaling pathway activation promotes improvement of locomotor function after spinal cord injury in rats. Neuroscience 169: 1046-1062, 2010.

30. Wahl EA, Schenck TL, Machens HG and Balmayor ER: VEGF released by deferoxamine preconditioned mesenchymal stem cells seeded on collagen-GAG substrates enhances neovascularization. Sci Rep 6: 36879, 2016.

31. Escudero C, Bertoglia P, Hernadez M, Celis C, Gonzalez M, Aguayo C and Acurio J: Impaired A2A adenosine receptor/nitric oxide/VEGF signaling pathway in fetal endothelium during late- and early-onset preeclampsia. Purinergic Signal 9: 215-226, 2013.

32. Khanabdali R, Shakouri-Motlagh A, Wilkinson S, Murthi P, Georgiou HM, Brennecke SP and Kalionis B: Low-dose aspirin treatment enhances the adhesion of preeclamptic decidual mesenchymal stem/stromal cells and reduces their production of pro-inflammatory cytokines. J Mol Med (Berl) 96: 1215-1225, 2018.

33. Kintiraki E, Papakatsika S, Kotronis G, Goulis DG and Kotsis V: Pregnancy-induced hypertension. Hormones (Athens) 14: 211-223, 2015.

34. Lu F, Longo M, Tamayo E, Maner W, Al-Hendy A, Anderson GD, Hankins GD and Saade GR: The effect of over-expression of sFlt-1 on blood pressure and the occurrence of other manifestations of preeclampsia in unrestrained conscious pregnant mice. Am J Obstet Gynecol 196: 396 e391-397; discussion 396 e397, 2007.

35. Maynard SE, Min JY, Merchan J, Lim KH, Li J, Mondal S, Libermann TA, Morgan JP, Sellke FW, Stillman IE, et al: Excess placental soluble fms-like tyrosine kinase 1 (sFlt1) may contribute to endothelial dysfunction, hypertension, and proteinuria in preeclampsia. J Clin Invest 111: 649-658, 2003.

36. Ohkuchi A, Hirashima C, Suzuki H, Takahashi K, Yoshida M, Matsubara S and Suzuki M: Evaluation of a new and automated electrochemiluminescence immunoassay for plasma sFlt-1 and PIGF levels in women with preeclampsia. Hypertens Res 33: 422-427, 2010

37. Venkatesha S, Toporsian M, Lam C, Hanai J, Mammoto T, Kim YM, Bdolah Y, Lim KH, Yuan HT, Libermann TA, et al: Soluble endoglin contributes to the pathogenesis of preeclampsia. Nat Med 12: 642-649, 2006.

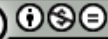

This work is licensed under a Creative Commons Attribution-NonCommercial-NoDerivatives 4.0 International (CC BY-NC-ND 4.0) License. 